\title{
Green Blocks Made of Recycled Construction Waste using Recycled Wastewater
}

\author{
Elgaali Elgaali*, Adel Al Wazeer \\ Civil Engineering Program, Higher Colleges of Technology, Dubai Men's College, Dubai, 10000, UAE
}

\begin{tabular}{l} 
A R T I C L E I N F O \\
\hline Article history: \\
Received: 07 December, 2020 \\
Accepted: 24 February, 2021 \\
Online: 10 March, 2021 \\
\hline
\end{tabular}

Keywords:

Sustainability

Waste

Recycling

\begin{abstract}
A B S T R A C T
This study tests the feasibility of manufacturing concrete blocks made of recycled materials. The paper is an extension of work originally presented in ASET conference in Dubai. The paper, depicts and analyzes how the characteristics of the blocks (strength/durability) are affected by the presence of recycled concrete ingredients (recycled aggregate (RA)) and recycled water $(R W)$. The recycled materials $(R A$ and $R W)$ were mixed in 16 different configurations; from each one 10 samples were prepared for testing. In each concrete configuration the RA and $R W$ gradually replaced the fresh materials at 25\%, 50\%, 75\%, and $100 \%$. The RA moderately impacted the bearing capacity but significantly impacted the durability. The results show that using recycled aggregate decreases the bearing capacity by 22\% (at the 100\% replacement), and the recycled water slightly affected the bearing capacity (at the 100\% replacement). To boost the durability, the ground granulated blast furnace slag (GGBS) was used, in the concrete mix, instead of the ordinary Portland cement (OPC). The GGBS was used at 3 magnitudes: $25 \%, 50 \%$, and $75 \%$ of OPC. As a result the carbon foot-print footprint $\left(1000 \mathrm{~kg} / \mathrm{m}^{3}\right)$ was significantly lowered. Besides, the strength and durability of the blocks are reasonably enhanced. Generally, producing blocks from recycled materials is economical and feasible. The use of GGBS helps to lower the carbon footprint and enhance the strength and durability.
\end{abstract}

\section{Introduction}

The volume of construction waste $(\mathrm{CW})$ produced in the countries of the Gulf Cooperation Council (GCC), especially in the UAE, is increasing due to on-going developments activities and construction projects. Dubai alone produces huge amount of waste from construction activities (5,000 tons/day). This amount accounts for around $70 \%$ of the total solid waste generated [1]. Almost the whole amount of the $\mathrm{CW}$ is dumped into landfills posing hazards to the local and regional environment. Therefore, there is a necessity to devise methods for utilization of this huge amount of the construction waste produced [2].

Worldwide many studies have been conducted looking for alternatives to reduce construction waste and hence preserve the natural resources [3], [4]. Completely recycling construction waste, is one of best alternatives have been tested. Recycling of construction waste preserves the virgin natural resources and reduces its negative impacts on the environment. Construction waste recycling gains importance because it provides the construction industry with huge amount of ingredients for

"Corresponding Author: Elgaali, P.O. Box: 15825, Dubai, UAE, 971 552493085, eelgaali@hct.ac.ae

www.astesj.com

https://dx.doi.org/10.25046/aj060207 construction applications (aggregate and sand). The recycled aggregate and sand are widely used now in the construction industry applications; road subbase, back-filling, and pipelines bedding material [5], [6]. Significant amount of research efforts have been directed to study the properties of these materials (sand and aggregate) and their effects on construction quality [7]-[14]. In general, compared to the fresh aggregate, the RA was found to have higher water absorption, lower bulk density, and lower specific gravity. The water absorption is higher due to the fact that the RA absorbs water available for hydration of cement. It is reported that water absorption greatly affects the workability and the strength of the concrete [8]. Opposite to that, a recent research reported that with thorough cleaning the RA can have low water absorption [9]. However, the outcome of the most of the research done show that the properties of concrete made of recycled materials (recycled concrete, RC) vary in wide limits, sometimes are even opposite, but generally, compared to the normal fresh concrete (NC), the RC was found to have reduction in compressive strength and increase in water absorption and porosity (decrease in durability) [11]-[13]. Nonetheless, the mechanical properties of concrete structures (cubes, cylinders, and beams) made from recycled materials (RM) is well documented, 
however blocks made from RM is not yet widely known. Therefore, the main objective of this paper is to examine the properties (bearing capacity and durability) of concrete blocks made of recycled materials.

Globally and in the UAE, hollow blocks are widely used as a building material in the construction of non-load-bearing walls. Blocks are produced with hollow centers to reduce weight and improve insulation. They are characterized to be light weight and require low maintenance. The block industry is expected to absorb huge amount of the recycled materials.

This paper also aims to test the feasibility of using recycled wastewater in blocks' manufacturing. Dubai generates huge quantity of wastewater every day (around 4 MGD). Presently, this large quantity of wastewater is treated, recycled, and widely reused in different activities such as: irrigation of the public greeneries, stabilization of loose soil, and more recent casting of concrete [15].

For long time, fresh water has been widely used in concrete industry. Unfortunately, nowadays fresh water, around the globe, neither comfortably obtainable nor affordable. Therefore, recycling and reusing of wastewater in concrete industry have been under investigation for a while. According to EN 1008 (2002) and ASTM C 94 the recycled wastewater is well qualified to be used in concrete mixing (Table 1) [16], [17]. Besides, the cost of the recycled water is less than the one of the potable water, especially in this region where the potable water is produced by desalination of the sea water. The properties of concrete - setting, hardening, strength, and durability - were proven to be drastically affected by the characteristics of the water used in concrete casting. However, few studies so far have focused on studying the effect of the recycled water on the concrete quality [1]. As such, this research aims to contribute to the body of literature that examines how the RA and RW impact the quality (strength/durability) of blocks made of recycled materials.

Reducing the carbon foot print (CFP) of the concrete industry was one of the goals of this study. The relatively high carbon foot print $\left(100 \mathrm{~kg} / \mathrm{m}^{3}\right)$ that cement (OPC) put on environment is already documented [9]. One approach to alleviate such high CFP is by replacing the OPC with a material has lower carbon foot print. The ground granulated blast furnace slag (GGBS), is one of the materials that is widely used to replace the cement to lower the carbon footprint and enhance the durability [9]. The GGBS is a secondary product derived from manufacturing process of steel. Therefore, it is used here, as a green material, to make the concrete more durable and reduce the CFP. Hence, excluding the tiny amount of the OPC that was not replaced, the concrete mixtures configured in this study practically could be considered completely recycled concrete or environmentally called "green concrete'.

The recycled aggregates and water (RA and RW) were used to prepare concrete samples according to the mix design given in Table 2. Sixteen mixes of concrete were designed and 160 specimens were prepared. In the concrete mixes $25 \%, 50 \%, 75 \%$, and $100 \%$ of the fresh aggregate and water were replaced by recycled aggregate and recycled water. In order to enhance the durability and carbon foot print $25 \%, 50 \%$, and $75 \%$ of the OPC in the concrete mixes were replaced by GGBS. The results are presented and discussed in section 3 of this paper.

\section{Materials and Methods}

\subsection{Recycled Aggregate Materials}

The recycled aggregate used in this research, was obtained from a recycling plant for demolition and construction waste in Dubai, UAE. Nowadays, almost the whole amount of the construction and demolition waste is recycled in aggregate of high-quality for customers across the country Figure 1.

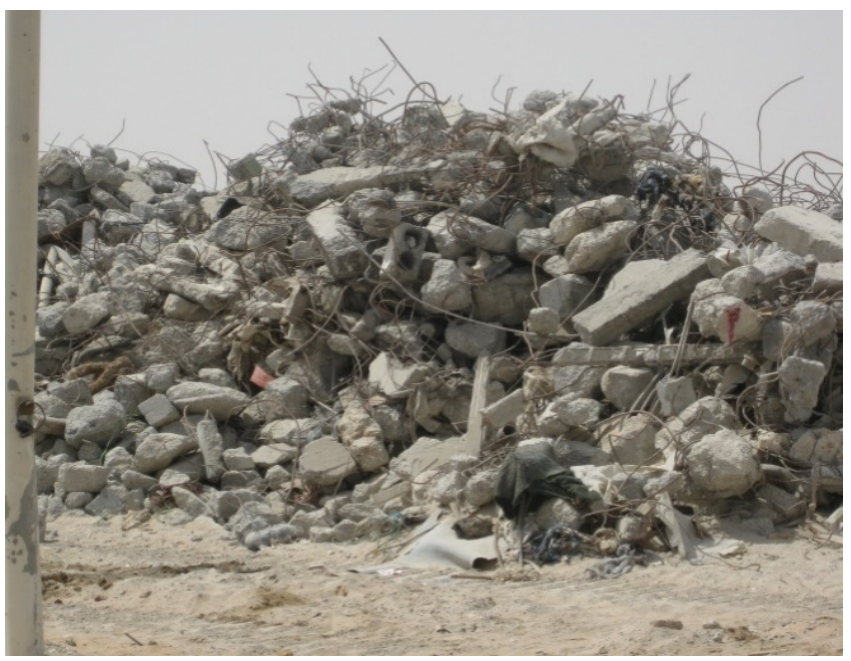

(a) Input Materials

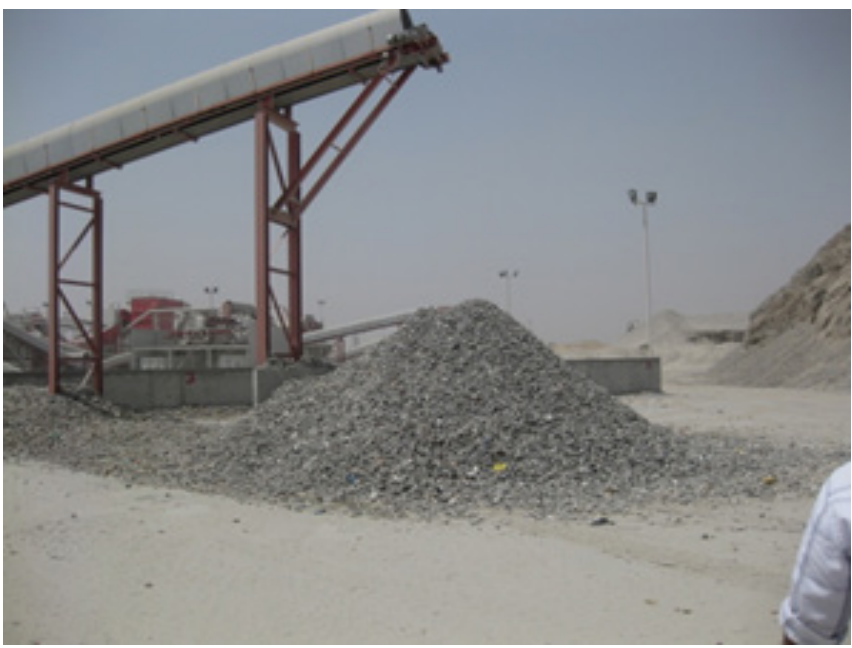

(b) Output Material

Figure 1: Recycling of Construction Waste in Dubai, UAE

In order to determine the quality of the RA, several samples were collected (grabbed), processed, cleaned, and mixed in representative samples for laboratory testing. Then the following tests were conducted:

- Sieve Analysis.

- Water absorption and Specific gravity.

- LA abrasion. 
Figure 2 shows the sieve analysis result. The figure shows that the RA does not meet the specifications set by Dubai Municipality. In order to use this materials, it has to be blended to meet the specifications.

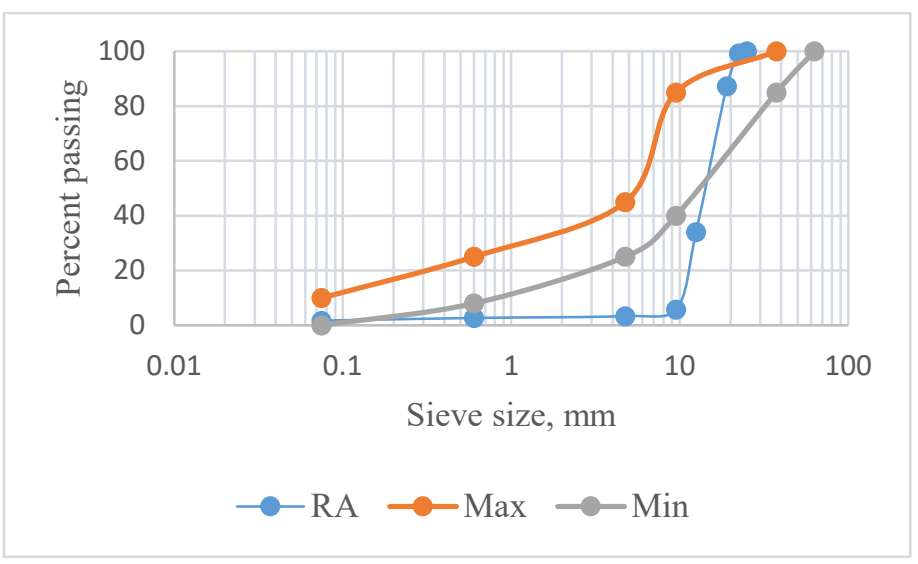

Figure 2: Sieve analysis results

Figure 3 shows the result of the water absorption and specific gravity test. Five representative samples were tested. The figure shows that the RA meets the specifications set by ASTM's construction standards. The values of water absorption are less than $2 \%$; the values of the specific gravity are greater than $2.6 \%$ (the permissible limits set by ASTM).

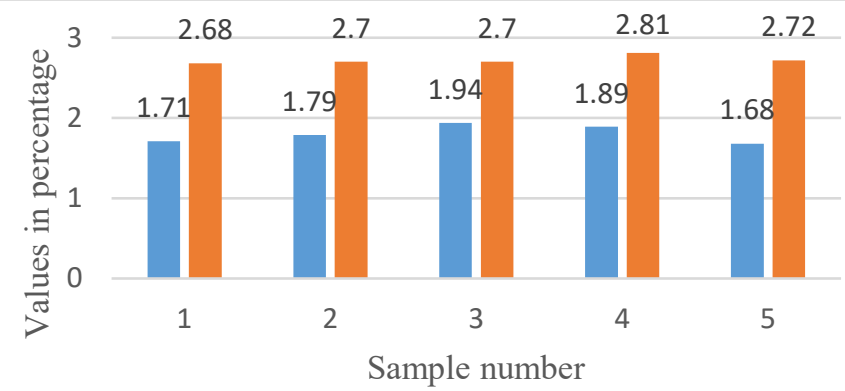

- Water absorption $\square$ Specific gravity

Figure 3: Water absorption and specific gravity test results

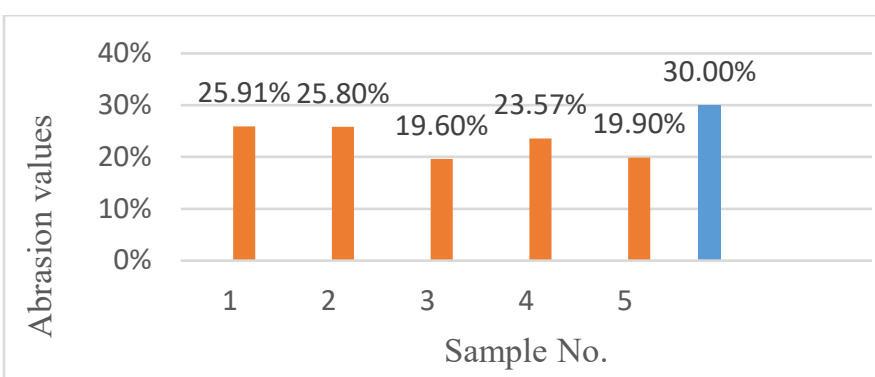

- Permissible Limit $\quad$ RA Samples

Figure 4: LA abrasion test results

Figure 4 shows the result of the LA abrasion test. Five representative samples were tested. The figure shows that the RA meets the specifications set by ASTM. The values of abrasion are less than $30 \%$ (the permissible limits set by ASTM).
However, the average measured density and water absorption of the recycled aggregate used in this study were found to be 2.51 $\mathrm{t} / \mathrm{m}^{3}$ and $1.8 \%$, respectively.

\subsection{Recycled Wastewater}

The water used in the concrete mixing in this research, was obtained from sewage treatment plant in Dubai. The wastewater was conventionally treated. In the conventional way, the wastewater is treated through different stages starting from primary treatment to advanced (tertiary) treatment. The advanced treatment is designed mainly to remove the nitrogen and the phosphorus to control eutrophication [18]. Compared to the standards (Chloride 1000, Sulfate 2000, Alkali carbonates and bicarbonates 1000, and Total dissolved solids $2000 \mathrm{mg} / \mathrm{L}$ ), the characteristics of the recycled water used in this study were found to be acceptable by the masonry blocks standards authority in Dubai [1]. Laboratory analysis results reported the following characteristics of the recycled water: pH 7.704 (standard usually ranges from 7 to 9), Chloride 480, Sulfate 197, Alkali carbonates and bicarbonates 132, and Total dissolved solids $1126.5 \mathrm{mg} / \mathrm{L}$. Table 1, shows the physical and chemical properties of the treated water used in this research.

Table 1: Physical and Chemical Properties of Treated Wastewater

\begin{tabular}{|l|c|c|c|c|}
\hline & Units & Min & Max & Average \\
\hline Temp & $\left({ }^{\circ} \mathrm{C}\right)$ & 18 & 25 & 20 \\
\hline $\mathrm{pH}$ & & 7.59 & 7.84 & 7.704 \\
\hline Cond. & $(\mathrm{uS} / \mathrm{cm})$ & 1,915 & 2,400 & 2203.82 \\
\hline TDS & $(\mathrm{mg} / \mathrm{l})$ & 1,007 & 1,218 & 1126.5 \\
\hline Turbidity & $(\mathrm{NTU})$ & 0.6 & 2.9 & 1.7 \\
\hline TSS & $(\mathrm{mg} / \mathrm{l})$ & 2 & 7 & 4 \\
\hline VSS & $(\mathrm{mg} / \mathrm{l})$ & 1 & 6 & 2 \\
\hline COD & $(\mathrm{mg} / \mathrm{l})$ & 23 & 33 & 27.0886 \\
\hline sCOD & $(\mathrm{mg} / \mathrm{l})$ & 24.2 & 31.4 & 26.975 \\
\hline cBOD5 & $(\mathrm{mg} / \mathrm{l})$ & 1.64 & 3.92 & 2.31 \\
\hline NH4-N & $(\mathrm{mg} / \mathrm{l})$ & 0.28 & 5.85 & 2.56 \\
\hline NO2-N & $(\mathrm{mg} / \mathrm{l})$ & 0.59 & 2.16 & 1.37 \\
\hline NO3-N & $(\mathrm{mg} / \mathrm{l})$ & 2.74 & 3.35 & 3.08 \\
\hline Total P & $(\mathrm{mg} / \mathrm{l})$ & 3.61 & 4.61 & 4.21 \\
\hline Chlorides & $(\mathrm{mg} / \mathrm{l})$ & 441 & 532 & 480 \\
\hline Sulfates & $(\mathrm{mg} / \mathrm{l})$ & 185 & 204 & 197 \\
\hline T-ALK & $(\mathrm{mg} / \mathrm{l})$ & 119 & 149 & 132 \\
\hline & & & & \\
\hline
\end{tabular}




\begin{tabular}{|l|l|l|l|l|}
\hline $\begin{array}{l}\text { Total } \\
\text { Hardness }\end{array}$ & $(\mathrm{mg} / \mathrm{l})$ & 248 & 300 & 278 \\
\hline
\end{tabular}

(Courtesy: Dubai Municipality, Dubai, 2017)

\subsection{Mixes Design}

The study was done in two phases: phase I where the concrete mixes were made of non-processed recycled materials (not sieved or cleaned). Phase II where the concrete mixes were made of processed materials (sieved and cleaned). However, the recycled materials were used to prepare four sets of concrete mixes according to the mix design given in Table 2. Each set consists of four mixes. In total sixteen mixes of concrete were prepared following the same proportions that used in the commercial manufacturing of the blocks. Usually, the blocks mix consist of the following quantities: coarse aggregate: $146 \mathrm{~kg}$ of $3 / 8$ " and $113 \mathrm{~kg}$ of 3/16"; Water: $20 \mathrm{~kg}$; sand: $56 \mathrm{~kg}$; and cementitious materials: $32 \mathrm{~kg}$. As required by the central laboratories in Dubai, out of each mix, ten specimens (blocks) were prepared for testing (160 specimens in total). The blocks are 6-inch hollow blocks (400 X $150 \times 200 \mathrm{~mm}$ ) (Figure 5). This size is selected, because it is the most widely used one in the UAE.

Table 2: Test Matrix

\begin{tabular}{|c|c|c|c|c|}
\hline Material Substituted & \multicolumn{4}{|c|}{ Percentage } \\
\hline Recycled Aggregates & $25 \%$ & $50 \%$ & $75 \%$ & $100 \%$ \\
\hline Recycled Water & $25 \%$ & $50 \%$ & $75 \%$ & $100 \%$ \\
\hline $\begin{array}{c}\text { Recycled } \\
\text { Water/Aggregate }\end{array}$ & $25 \%$ & $50 \%$ & $75 \%$ & $100 \%$ \\
\hline GGBS & $25 \%$ & $50 \%$ & $75 \%$ & $100 \%$ \\
\hline
\end{tabular}

(The GGBS was replaced in a mix of $100 \%$ recycled water and $25 \%$ of recycled aggregate)

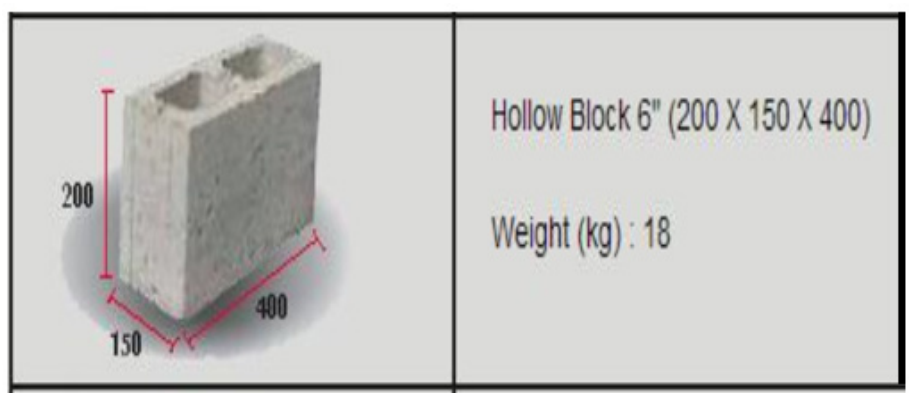

Figure 5: 6-inch hollow block dimensions and weight

In the concrete mixes the RA and RW gradually replace the fresh ones at the following percentages: $25 \%, 50 \%, 75 \%$, and $100 \%$. Table 2 shows these replacements more clearly in details. In order to determine the extent of the impact of the recycled materials on the characteristics of the blocks, a mix was prepared from fresh materials and used as a control mix (baseline).
The bearing capacity of each block was tested on a $3000 \mathrm{kN}$ capacity Wizard basic hydraulic machine (Figure 6). Load was applied gradually and continuously until failure.

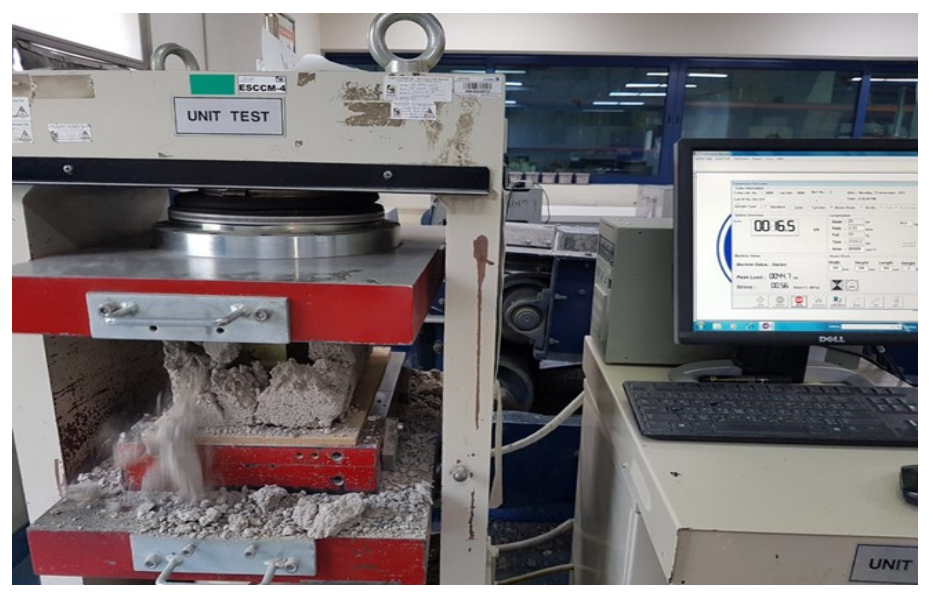

Figure 6: Testing the block's bearing capacity

\section{Results and Discussion}

\subsection{Effects of Recycled Aggregate}

In Phase I, the results show a gradual reduction the axial strength of the block corresponding to the gradual increase in the percentage of the recycled aggregate. It is depicted in Figure 7 that the failure in the bearing capacity (strength) of the blocks ranges from $23 \%$ to $46 \%$. The highest reduction was recorded to be associated with the blocks made of $75 \%$ replacement. It worth mentioning that the high contents of sand in the RA used, led to the failure of the mix with $100 \%$ replacement at early stage (casting stage). However, the results presented are highly supported by some other studies conducted previously [8]-[10]. They documented that the gradual reduction in the axial strength of the mixes directly related to the increase of the percentage of RA. They also depicted that any replacement of RA below $20 \%$ has minor effect on the axial strength.

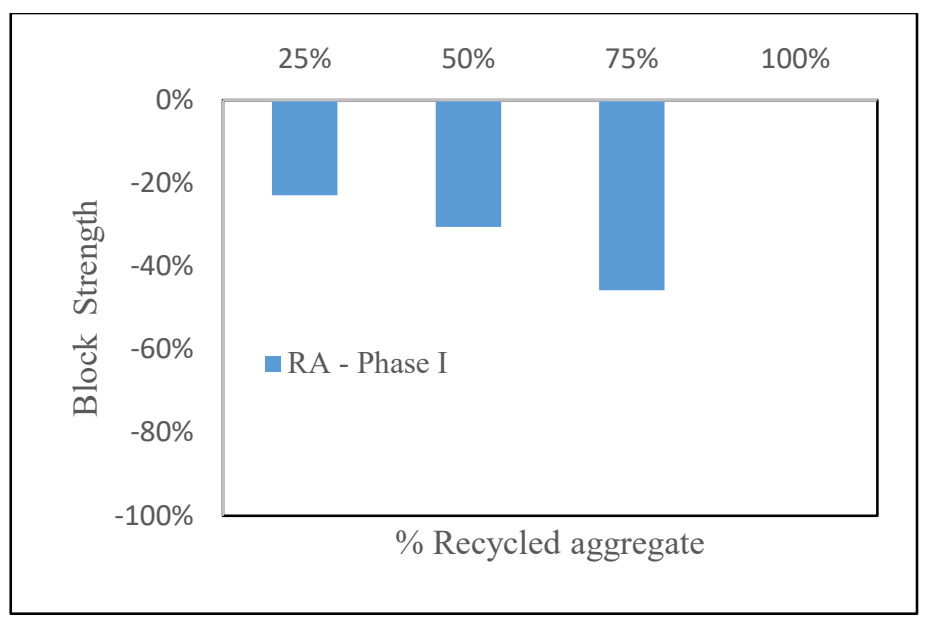

Figure 7: Effect of $\%$ recycled aggregate on bearing capacity 
In phase II, the results support that the gradual reduction the axial strength of the block corresponding to the gradual increase in the percentage of the recycled aggregate. For better illustration, the results of both phase I and Phase II are compared in Figure 8. The figure shows how the RA impacts the compressive strength of the blocks. The results of phase I show how the presence of sand and dust in the samples of the RA used, led to a significant reduction in the compressive strength extending from $23 \%$ to $46 \%$. The results of Phase II show considerable improvement in the blocks quality (Figure 8). At 25\% replacement, the block's quality improved from $23 \%$ drop to $9 \%$ drop in in the strength; at $100 \%$ replacement quality of the blocks improved from $100 \%$ drop to $22 \%$ drop in the strength. In general the magnitude of enhancement in strength extends from $14 \%$ to $88 \%$. The enhancement in the blocks' quality is mainly caused by the deep cleaning the RA undergone, in phase II, which results in high removal of sand and dust.

In general, the results presented confirm the inverse relation that governs the magnitude of the block's strength and the percentage of the recycled aggregate (RA).

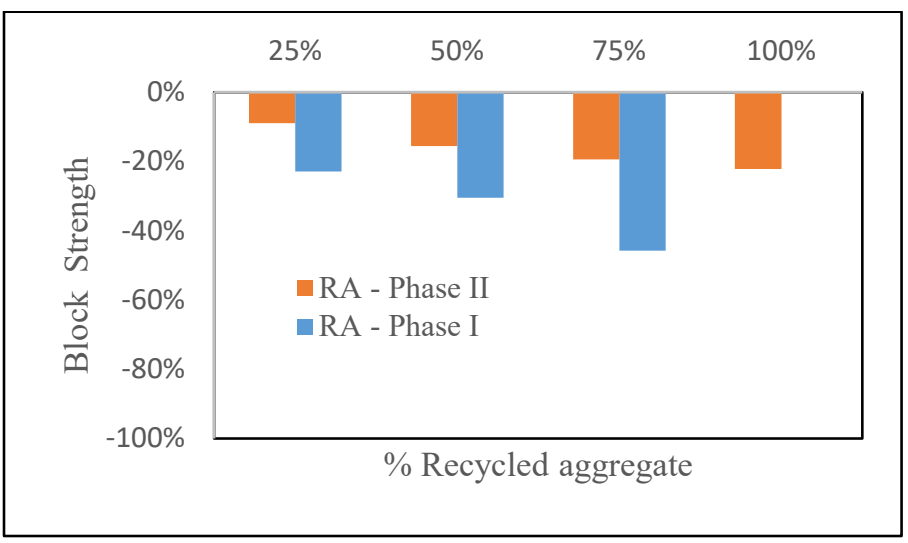

Figure 8: Effect of $\%$ recycled aggregate on bearing capacity

\subsection{Effect of Recycled Sand}

In Phase I, the results depict how the block's strength was drastically dropped when the percentage of the recycled sand (RS) increased. It is seen in Figure 9 that the failure in the bearing capacity (strength) of the blocks ranges from $90 \%$ to $95 \%$ when sand is replaced by $25 \%$ and $50 \%$ respectively.

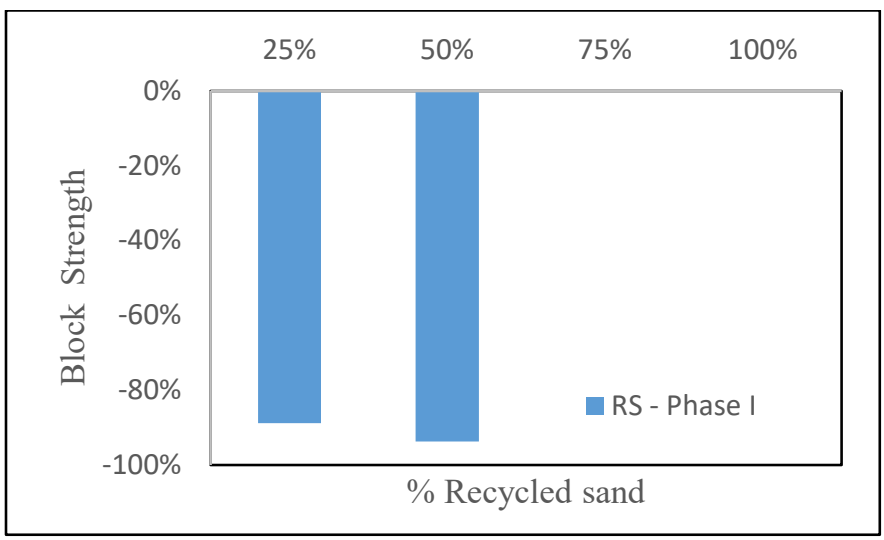

Figure 9: Effect of \% recycled sand on bearing capacity
The presence of clay and silt at high levels in the recycled sand used in this study, caused the mixes with $75 \%$ and $100 \%$ recycled sand fail at early stage (casting stage). This result is supported by previous research [9].

The results of phase II show how the quality of the RS hindering the process of making sustainable blocks from completely recycled materials. For better illustration, the results of both phase I and Phase II are compared in Figure 10. The figure shows how the RS impacts the compressive strength of the blocks. The results of phase I show how the presence of clay and silt in the samples of the RS used, led to a significant reduction in the compressive strength. The results of Phase II show slight improvement in the blocks quality (Figure 10). At $25 \%$ replacement, the block's quality improved from $90 \%$ drop to $43 \%$ drop in in the strength; at $50 \%$ replacement quality of the blocks improved from $95 \%$ drop to $69 \%$ drop in the strength. In general, the enhancement in the blocks' quality is of small magnitude signifying that using RS at any percentage leads to lower the blocks' quality.

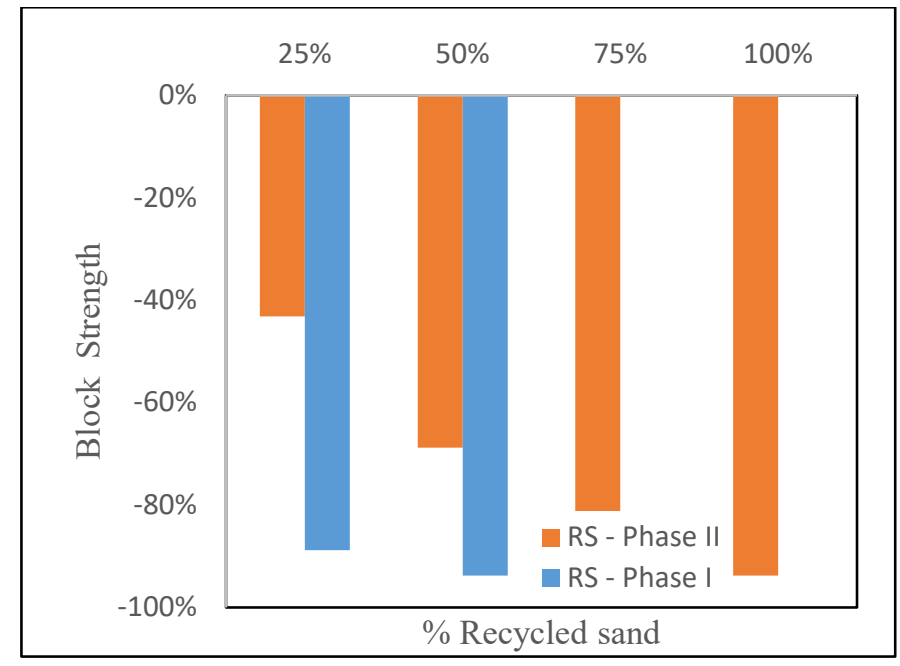

Figure 10: Effect of \% recycled sand on bearing capacity

\subsection{Effect of Recycled Wastewater}

Figure 11 shows that replacing the fresh water in concrete mixes with $100 \%$ of RW has very minor impact on the block's quality (bearing capacity). This result signifies the high quality of the RW that characterized by low concentrations of sulfates and chlorides. The deleterious effects of the sulfates and chlorides on the weathering and the durability of concrete are well documented. The high concentrations of the total dissolved solids (TDS) in any water, used for concrete mixing, tend to make the concrete mix less durable [19]. However, the main properties of the RW water used in this study, are presented here for better understanding of the direction of the results in this section. The properties include $\mathrm{pH}$ of 7.704, Chloride of $480 \mathrm{mg} / \mathrm{l}$, sulfate of $197 \mathrm{mg} / \mathrm{l}$, Alkali carbonates and bicarbonates of $132 \mathrm{mg} / \mathrm{l}$, and Total dissolved solids of $1126.5 \mathrm{mg} / \mathrm{l}$; compared to standard values of $7-9,1000$, 2000,1000 , and 2000 respectively. The results presented, clearly show that the RW is characterized by high quality and can be safely used in concrete industry. 


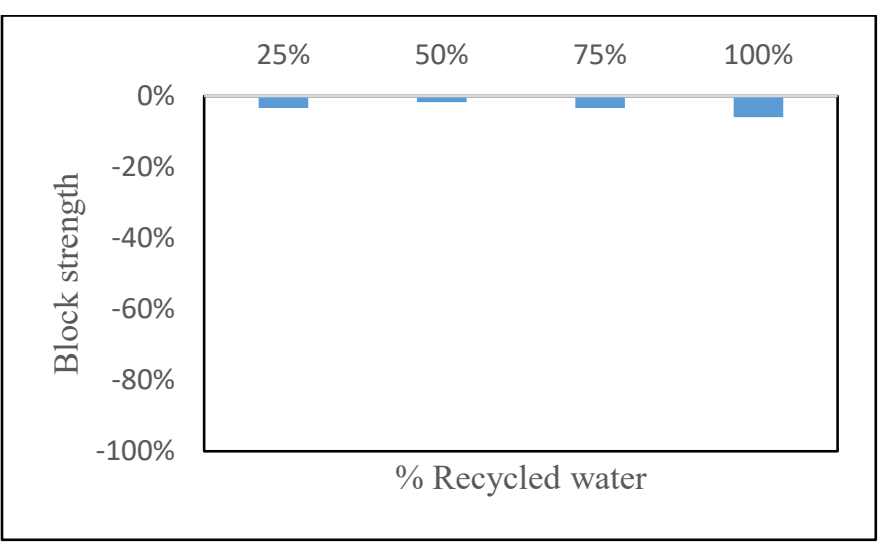

Figure 11: Effect of percentage of recycled water on block's bearing capacity

\subsection{Effects of Sulfates and Chlorides}

To study the effects of salts on the blocks' quality, the concentrations of the sulfates $\left(\mathrm{SO}_{3}\right)$ and chlorides $(\mathrm{Cl})$ were determined and compared to the standards developed by the British standards (BS 1881: Part 124). In 10 specimens the average concentrations of the chlorides and sulfates are determined to be $0.04 \mathrm{mg} / \mathrm{l}$ and $0.25 \mathrm{mg} / \mathrm{l}$ respectively. The BS set maximum concentration level (MCL) of $0.05 \%$, by mas of concrete, for the chlorides, and $0.5 \%$, by mass of concrete, for the sulfates. Thus, the result obtained here clearly show that the levels of both $\mathrm{SO}_{3}$ and $\mathrm{Cl}$ do not exceed the standards set by the BS. However, both phases I and II show similar results regarding the levels of the chlorides and sulfates.

\subsection{Effects of $G G B S$}

Tests conducted to examine the effects of replacing the ordinary cement (OPC) by GGBS. In the concrete mix with $25 \%$ RA, $25 \%, 50 \%$, and $75 \%$ of the OPC were replaced by GGBS. As shown in Figure 12, replacing the OPC with $75 \%$ GGBS had no effect on the durability, besides no improvement had been shown on the block strength.

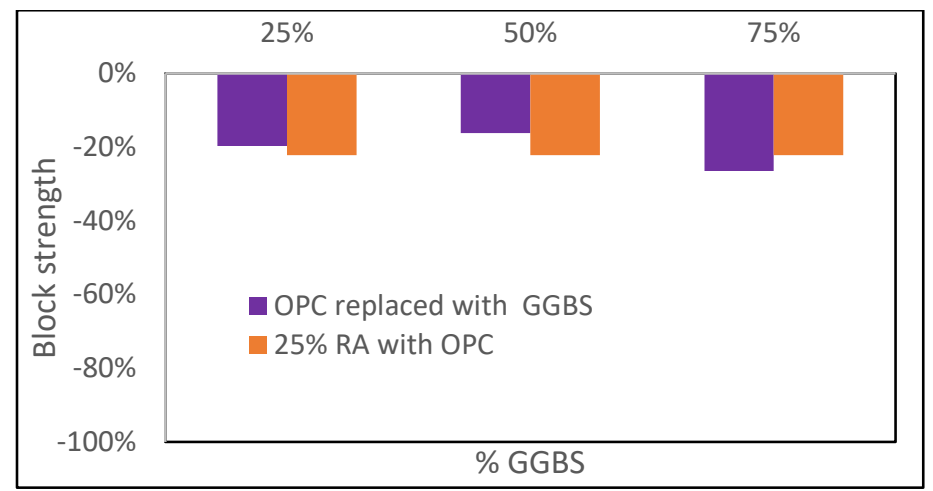

Figure 12: Effect of percentage of GGBS on block's bearing capacity

The other two mixes (25\% and 50\%) both showed improvement in the block strength. As shown (Figure 12), the quality of the blocks improved and the reduction in the axial strength decreased from $22 \%$ to $19 \%$ (at $25 \%$ GGBS) and from $22 \%$ to $16 \%$ (at $50 \%$ GGBS). As reported, the magnitude of improvement falls in the range of 3\%-6\%. However, the result show that when the GGBS is more than $50 \%$ its influence is negligible.
In general, GGBS was found to boost the durability in any concrete mix. Therefore, to manufacture blocks with high quality, from recycled materials, the blocks industry is encouraged to use GGBS. Besides, the economical (lower cost) and environmental (lower carbon foot print) benefits obtained when GGBS is used instead of OPC.

\section{Summary and Conclusions}

This study tests how concrete blocks of high quality could be manufactured from ingredients recycled from construction waste (concrete). The paper, depicts and analyzes how the characteristics of the blocks (strength/durability) are affected by the presence of recycled concrete ingredients (recycled aggregate (RA)) and recycled water (RW). The RA moderately impacts the bearing capacity but significantly impacts the durability, while the RW negligibly impacts both. In general it was found that producing blocks from recycled materials is economical and feasible. However, the following specific conclusions are drawn:

\subsection{Recycled Aggregate}

How the RA affects the qualities of the blocks (strength/durability) was investigated and depicted. The presence of dust on the surface of the RA led to significant drop in the blocks qualities (strength/durability). The magnitude of the drop was estimated to fall in the range of $23 \%$ to $46 \%$. When the RA is furtherly sieved, processed, and cleaned the blocks' quality improved a lot. The magnitude of the improvement was estimated to fall in the range of $14 \%-63 \%$. It is documented that using RA at magnitude less than $20 \%$ has intangible impact on the quality of the blocks.

\subsection{Recycled Sand}

How the recycled sand (RS) affects the qualities of the blocks (strength/durability) was investigated and depicted. The impacts of RS on blocks; quality was enormous. The impact of RS is very huge ranges between $43 \%$ - 95\% reduction in the compressive strength. The RS was found to have stronger impact on the blocks' quality when compared to RA and RW. It is documented that using RS at any quantity heavily affects the blocks' quality.

\subsection{Recycled Wastewater}

How the recycled water (RW) affects the qualities of the blocks (strength/durability) was investigated and depicted. The RW used, is of high quality that matches the standards set by the international and local (Dubai) organizations that manage the masonry blocks industry. The very low levels of the sulfates and chlorides caused the quality of the blocks to be insensitive to the recycled water. However, it can be stated that the high quality of the RW almost has no impact on the blocks' quality (strength and durability). It is documented that using RW at magnitude less or equal to $100 \%$ has intangible impact on the quality of the blocks.

\subsection{Sulfates and Chlorides}

The concentrations of the sulfates $\left(\mathrm{SO}_{3}\right)$ and chlorides $(\mathrm{Cl})$ in the blocks, were determined and compared to the standards developed by the international (BS) and local (Dubai) 
organizations that manage the masonry blocks industry. The levels of the $\mathrm{SO}_{3}$ and $\mathrm{CL}$ was found to meet the standards set internationally and locally. However, the current levels $(0.04 \mathrm{mg} / 1$ and $0.25 \mathrm{mg} /$ ) have no impacts on the blocks quality.

\subsection{GGBS}

Using the ordinary cement (OPC) in concrete mixes, adversely affects the local and regional environment (increase the carbon footprint). Also, using recycled materials in concrete mixes has huge impact on the ddurability. Therefore, GGBS was tested to replace the OPC to preserve the blocks' quality (durability) and save the environment (reduce CFP). Replacing the OPC with GGBS by percentage exceeds $50 \%$ has no positive effect on the quality of the blocks. The outcome of this study documents that using GGBS, in block manufacturing process, helps to lower the carbon footprint and enhance the strength and durability.

\section{Conflict of Interest}

No conflict of interest in publishing this paper.

\section{Acknowledgment}

The authors would like acknowledge the contribution of Dubai Men's College (DMC) - Higher Colleges of technology, and the following students: Abdulla Taher, Hussain Habib, Mohammad Fardan, Saif Nasser, and Zayed Almadhanni.

\section{References}

[1] E. Elgaali, A. Al Wazeer, "Green blocks made of recycled waste phase II," Advances in Science and Engineering Technology International Conference, ASET, Dubai, UAE, 1-5, 2020, DOI: 10.1109/ASET48392.2020.9118227.

[2] E. Elgaali, A. Alsharid, A. Julfar, "Green blocks made of recycled waste," Advances in Science and Engineering Technology International Conference, ASET, Dubai, UAE, 1-5, 2018, DOI: 10.1109/ICASET.2018.8376773

[3] A. Al-Hajj, K. Hamani, "Material waste in the UAE construction industry: main causes and minimization practices," Architectural Engineering and Design Management, 7(4), 2011, doi: 10.1080/17452007.2011.594576.

[4] V. Tamab, M. Soomro, A. Evangelistadc, "A review of recycled aggregate in concrete applications (2000-2017)," Construction and Building Materials, 172, 272-292, 2018, doi: 10.1016/j.conbuildmat.2018.03.240

[5] R. OBE, J. Brito, R. Silva, C. Lye, "Use of recycled aggregates in geotechnical applications," Sustainable Construction Materials, 419-450, 2019, doi: 10.1016/B978-0-08-100985-7.00011-X.

[6] V. Panchal, V. Kulkarni, A. Kulkarni, A. Kumar, "Use of construction demolition waste in pavement," International Journal of Advanced Research in Science, Engineering and Technology, 4(12), 4956-4964, 2017, ISSN: 2350-0328.

[7] R. V. Silva, J. R. Jiménez, F. Agrela, J. de Brito, "Real-scale applications of recycled aggregate concrete," New Trends in Eco-efficient and Recycled Concrete, 573-589, 2019, doi: 10.1016/B978-0-08-102480-5.00021-X.

[8] Said Kenai, Waste and supplementary cementitious materials in concrete, Woodhead, 2018.

[9] E. Mohamed, E. Elgaali, "Sustainable concrete made of construction and demolition wastes using recycled wastewater in the UAE" Journal of Advanced Concrete Technology-Japan, 10, 110-125, 2012. DOI:10.3151/jac .10 .110

[10] A. Hassan, A. Nabil, H. Abdulrazaq, F. Juma, M. Salem, Developing Design Criteria for Utilization of Construction and Demolition Wastes in Construction Applications, Thesis, Higher Colleges of Technology, 2019.

[11] C. Pellegrino, F. Faleschini, C. Meyer, "Recycled materials in concrete," Developments in the Formulation and Reinforcement of Concrete, 19-54, 2019, doi: 10.1016/B978-0-08-102616-8.00002-2.

[12] E. Ledesma, J. Jiménez, J. Ayuso, J. Rodriguez, "Maximum feasible use of recycled sand from construction and demolition waste for eco-mortar production - Part-I: Ceramic masonry waste," Journal of Cleaner Production, 87(1), 692-706, 2015, DOI: 10.1016/j.jclepro.2014.10.084.
[13] P. Chindaprasirt, T. Cao, Reuse of recycled aggregate in the production of alkali-activated concrete. Handbook of Alkali-Activated Cements, Mortars and Concretes, Woodhead, 2015.

[14] M. Malešev,V. Radonjanin, S. Marinković, “ Recycled concrete as aggregate for structural concrete production," Sustainability, 2(5), 1204-1225, 2010 doi: $10.3390 / \mathrm{su} 2051204$

[15] C. Tortajada, "Contributions of recycled wastewater to clean water and sanitation sustainable development goals," npj Clean Water, 3, 22, 2019, doi: 10.1038/s41545-020-0069-3

[16] EN 1008, British Standards, Mixing water for concrete specification for sampling, testing and assessing the suitability of water, including water recovered from processes in concrete industry, as mixing water for concrete. 2002.

[17] ASTM C 94, Standard test specification for ready-mixed concrete, American Society for Testing and Materials, Philadelphia, 1994

[18] M. J. Hammer Sr., M. J. Hammer Jr., Water and Wastewater Technology, Prentice Hall, 2003.

[19] A. Sales, F. R. De Souza, "Concrete and mortars recycled with water treatment sludge construction and demolition rubble," Construction and building materials, 23, 2326-2370, 2009, doi:10.1016/j.conbuildmat.2008. .11 .001 